\title{
Master Narratives, Ethics, and Morality
}

\author{
Moin Syed \\ University of Minnesota \\ Monisha Pasupathi \\ University of Utah \\ Kate C. McLean \\ Western Washington University
}

To appear in

L. Jensen (Ed.), The Oxford Handbook of Moral Development: An Interdisciplinary Perspective. New York: Oxford University Press.

Version Date: 10/06/17

Contact: moin@umn.edu,monisha.pasupathi@psych.utah.edu, kate.mclean@wwu.edu 


\begin{abstract}
In this chapter we explore how master narratives have ethical and moral implications, and how master narratives can provide a way for researchers to look at the intersections of culture, ethics, morality, and individual development. We make this case by advancing three propositions about the relation among master narratives, ethics, and morality: 1) Master narratives are fundamentally about ethics in that they outline and convey culturally held ideas about the nature of a good life; 2) While all master narratives are grounded in ethics, not all master narratives are moral; and 3) Despite proposition 2, master narratives can come to exert moral force. We first describe the master narrative framework, and then follow with a detailed discussion of the three propositions. Our intent is that this integration of master narratives with moral development will help researchers in both areas to think about their work in new ways.
\end{abstract}

Keywords: Master Narrative, Personal Narrative, Ethics, Morality, Identity, Culture 
Shortly after I turned 18 years old I left my parents' home and went away to college. I was eager for the freedom and autonomy to do as I pleased. But I was rather immature and not very into school, so I mainly used that freedom to party, to the extent that it interfered with my schooling. I stopped doing my homework, infrequently attended classes, and did not even show up for my calculus final. After three straight quarters of academic probation, I was kicked out of the school, having accumulated a 1.32 GPA. My parents were naturally upset, in part because me being away from college was a financial burden. But I had a stable, good-paying job, so I remained in the college town, lived with friends, worked full-time, and partied until I more or less got it out of my system. After a year of this I felt ready to attend school, so enrolled in the local community college. Once I began, I was committed, getting nearly straight A's. I ultimately transferred to a four-year university and finished my B.A., then went on to complete my master's and Ph.D. Most people are quite surprised when I tell them that getting kicked out of college was the best thing that ever happened to me.

Is this story about morality? Is it about ethical conduct, or notions of the good life? When taken on the surface, perhaps not. It appears to be one person's—let's call him Ronald—story about how a low point in life, a seeming failure, was turned into an opportunity to thrive. The story is one of redemption, which it turns out is a type of story that is quite popular in American culture, so much so that it operates as a master narrative in the U.S. (McAdams, 2006). Master narratives have been defined as "culturally shared stories that guide thoughts, beliefs, values, and behaviors” (McLean \& Syed, 2015, p. 323). Master narratives provide a template for how to tell a story, a good story about what it means to be a part of a particular cultural community; a story of one's life and how it fits with the cultural definition of success. The above story conforms to the master narrative of redemption and has a happy ending - and in American culture, this is a good story. But, the experience it relates is not without cost: the psychological challenges associated with the uncertainty of being expelled from school, the social violation of leaving school, the relational threat to the parents, and the squandering of limited financial resources. All of these costs reflect broader ethical and moral concerns. Additionally, other ethical and moral issues don't arise or remain unsaid in the story as told above - the presumption of autonomy to make decisions about one’s own life, and the privilege intrinsic to partying without 
repercussions. Further, the redemptive ending works in part by depicting the narrator as having returned to an expected 'good life' (strong academic performance) after his detour. Thus, parts of the story are redeemed (the violation of leaving school), while others are not (squandering the financial resources of the family).

In this chapter we explore how master narratives have ethical and moral implications, and can provide a way for researchers to look at the intersections of culture, ethics, morality, and individual development. We make this case by advancing three propositions about the relation among master narratives, ethics, and morality: 1) Master narratives are fundamentally about ethics in that they outline and convey culturally held ideas about the nature of a good life; 2) While all master narratives are grounded in ethics, not all master narratives are moral; and 3) Despite proposition 2, master narratives can come to exert moral force. We first describe the master narrative framework, and then follow with a detailed discussion of the three propositions. Our intent is that this integration of master narratives with moral development will help researchers in both areas to think about their work in new ways.

\section{A Narrative Framework for Development: Personal and Master Narratives}

Narrative psychology is an umbrella term for a variety of theoretical and methodological approaches to understanding the psychological significance of stories. The bulk of this work, however, has focused on individual's personal, autobiographical narratives in relation to wellbeing, personality, and development. For example, narrative psychologists examine both how stories serve as representations of individuals' identities as well as how the situated process of telling stories serves to construct and refine identities (McLean \& Pasupathi, 2012; McLean, Pasupathi, Pals, 2007; Schachter, 2015; Thorne \& Nam, 2006; see also DiBianca Fasoli, this volume for a complementary view). Within narrative psychology, stories are viewed as ongoing 
reconstructions of the personal past in light of current concerns and future prospects (McAdams, 2013). That is, stories are not evaluated with respect to their veracity or faithfulness to what "actually happened" at the time of the remembered event. Rather, stories are modulated, and modified over time, through the process of autobiographical reasoning. Autobiographical reasoning is a broad family of processes (e.g., meaning-making, constructing self-event connections, personal growth) that capture the ways in which people make sense of their personal past, and is considered a primary mechanism through which stories become integrated into individuals’ identities (Habermas \& Köber, 2015).

Personal narratives have long been seen as fundamentally intertwined with morality and moral identity, in part because narratives and the associated process of autobiographical reasoning serve to make sense of, and justify, actions and reactions, which can only be done with reference to what actions and reactions make sense on some kind of broader level beyond the individual life (Baumeister et al., 1990; Bruner, 1990; DiBianca Fasoli, this volume; Freeman, 1993; Laible \& Thompson, 2002; Pasupathi \& Wainryb, 2010; Reese et al., 2007; Tappan \& Packer, 1991; Wainryb et al., 2005). Thus, in narrating morally relevant experiences, people make sense of their own and others actions and reactions in a variety of ways (Jensen \& McKenzie, 2016), depending partly on the nature of the experience being narrated (e.g., victim vs. perpetrator; Wainryb et al., 2005; Baumeister et al., 1990; Recchia et al., 2013), and partly on the social, cultural, and historical context in which the narrative is constructed (Pasupathi, Wainryb, Bourne, \& Posada, in press; Recchia, Wainryb, Bourne \& Pasupathi, 2014; see also Nisbett \& Cohen, 1990).

For example, in typical samples from industrialized western countries, adolescents and adults narrate events where they harmed other people with references to conflicting goals, 
differing perspectives, and imperfect links between intention, action, and outcomes. The resulting narratives about harm acknowledge wrong-doing, but leave room for maintaining a sense of the self as a good person who sometimes makes mistakes. By contrast, youth growing up in violent contexts are prone to narrating the same types of events quite differently, specifically in ways that emphasize reciprocity and revenge. The highly reciprocal, vengeful narratives that make sense of harm-doing in violent settings are likely to contribute to cycles of harm (Govier, 2002; Hammack, 2011; Nisbett \& Cohen, 1990; Pasupathi et al., in press). These examples highlight how individuals' personal narratives of morality provide a window into both individual developmental processes (e.g., Pasupathi \& Wainryb, 2010), and the way that those processes are shaped by, and consequently shape, master narratives (Pasupathi et al., in press). Those master narratives, in contrast to personal narratives, are our focus here.

\section{Master Narratives: Culture, Power, and Agency}

The variations in personal narratives point to the central role of cultural context in the construction of personal narratives, which can be conceptualized in a framework of master narratives, which are culturally shared templates for stories that guide thoughts, feelings, and actions (Hammack, 2008; McAdams, 2006; McLean \& Syed, 2015; Thorne \& McLean, 2003). These stories are not about individual personal experiences but rather serve as broad cultural templates for how to tell particular types of stories, both in content and in structure - an example of which we pointed to with the opening story: redemption. One major advantage of conceptualizing cultural dimensions in narrative terms is that it places the analysis of culture on common ground with the analysis of personal narratives (McLean \& Syed, 2015). Furthermore, one can 'see' master narratives in personal stories; for example, in the cases in the paragraph above we see the possibility for redemption from wrong-doing, and the reciprocal antagonism 
between competing groups. These are larger cultural stories that are partly maintained by the individuals who story their lives to fit these templates.

In describing their master narrative framework, McLean and Syed (2015) outlined five core principles of master narratives: utility, ubiquity, invisibility, compulsory, and rigidity. In brief, master narratives provide information of how one ought to be and how one's stories ought to unfold (utility); they permeate many aspects of society, in family life, institutions, and the media (ubiquity); they are cast as natural, so they are rarely even noticed or named by those who align with them (invisibility); it is expected that most members of a society will adhere to them, and there are often real risks to deviating and endorsing an alternative narrative (compulsory); and they gain their power from being resistant to change in order to maintain the current system (rigidity). As we illustrate throughout this chapter, these five principles work together to give master narratives their social power for individual lives.

There are three critical aspects of master narratives, both in general and with respect to our application to questions of ethics and morality (McLean \& Syed, 2015; Syed, 2016). First, the master narrative framework is a cultural model, in that it places meaning and context at the center of analyses rather than the periphery (Shweder, 2000). Culture in the master narrative framework is not a "top-down" exogenous variable that exerts force on basic psychological process (cf., Bronfenbrenner, 1979; Markus \& Kitayama, 1991). Rather, the emphasis is on processes of mutual interaction and embeddedness of individuals and societal factors- that individual and culture are so deeply intertwined that they cannot be productively separated. Second, the master narrative framework asserts that societal power dynamics must lie at the center of the analysis. Master narratives are not neutral. In governing what is good, just, and acceptable in society, they reinforce the norms established by those who hold social power. 
Third, following the social power of master narratives, master narratives set substantial constraints on individual agency to develop an identity and live a good life. Indeed, in accordance with the principle of invisibility, master narratives can provide a false sense of agency, as they are often unconsciously internalized and subsequently cast as one’s own, autonomous choice. These three critical features, culture, power, and agency, will be further elaborated as we apply the master narrative framework to moral development.

\section{Application of the Master Narrative Framework to Moral Development}

Given the definition and conceptualization of master narratives, namely that they are prescriptions about how a life ought to be lived, there are clear connections to moral development. Below we advance three propositions on master narratives and moral development. In doing so, we explicitly connect to existing models of moral development, namely ethics (Appiah, 2006; Jensen, 2011) and domain theories (Smetana, 2006).

\section{Proposition 1: Master narratives are fundamentally about ethics in that they outline and convey culturally held ideas about the nature of a good life.}

How ought a life be lived? What constitutes a good life? This question is fundamentally governed by culturally defined ethical principles. Ethical principles consist of a broad set of norms that outline the nature of a good life, in terms of thoughts, feelings, and actions that cultivate virtue and other socially desirable traits (Appiah, 2006; Wolf, 1982). Morality, in contrast, is a subset of ethics more narrowly focused on judgments of interpersonal behavior (Appiah, 2006; Dworkin, 1986), specifically the principles of fairness/justice and beneficence/care. We recognize that not all theorists would necessarily endorse such a clear distinction between ethics and morals (e.g., Jensen 2011; Narvaez \& Lapsley, 2014), as the distinction can be murky. However, we draw a sharp distinction between them as we develop our 
propositions because a) we believe meaningful distinctions can be made and c) making such distinctions is a useful exercise for understanding how master narratives that appear to not pertain to morality can come to exert moral force. Accordingly, in arguing for the first proposition we focus on the broader category of ethics, and how ethics are intertwined with the concept of master narratives.

Recall that master narratives are defined as "culturally shared stories that guide thoughts, beliefs, values, and behaviors” (McLean \& Syed, 2015, p. 323). This definition of master narratives is intentionally broad and somewhat vague, because the concept of master narratives can be applied at all levels of social behavior, from broad national-cultural norms to highly specific work/career settings ${ }^{1}$. A key word in this definition, however, is guide; master narratives act as a guide for what is good, optimal, and valued. In this sense, master narratives are similar to the cultural concept of biography and life scripts (Arnett,2016; Habermas \& Reese, 2015; Hatiboğlu \& Habermas, 2016; Ottsen \& Berntsen, 2014). A major distinction between the cultural concept of biography perspective and the master narrative perspective is that the latter focuses more centrally on the evaluative aspects that render some biographies better than others, and the related concerns with how societal power dynamics create and reinforce those guides. For example, the cultural concept of biography and life scripts focus predominantly on positive events, presumably because the expectation of negative events occurring is less common in the populations under study. Thus, deviations from the cultural script come in the form of nonnormative life events (e.g., getting kicked out of college or fired from one’s job). In contrast, the

\footnotetext{
${ }^{1}$ An example that will be familiar to most readers of this chapter is doctoral education: a talented but naïve student enters the program, learns basic skills, develops a program of research, suffers through a preliminary examination, laborers over a dissertation, and experiences anxiety over the job search until she is ultimately rewarded with a satisfying career. Participating in the narrative and internalizing it then leads to socializing it to the next generation, thereby maintaining the master narrative (cf. rigidity), and marginalizing those who do not follow it (e.g., having a child while in graduate school, not obtaining an academic career post-graduation). But this master narrative only has meaning within this particular context, so it is heavily localized.
} 
master narrative framework specifies that some life courses are more highly valued within society than are others, and that what might be identified as the normative life course may not actually apply to those from marginalized background due to unequal access to power and opportunity.

Arnett (2016) recently integrated the work of cultural life scripts with master narratives by proposing that life stages, or how cultures delimit and conceptualize different sections of the lifespan, serve as a master narrative for the life course. Through a historical and cultural analysis, Arnett concluded that life stages have been, and continue to be, ubiquitous throughout human culture. Although they vary in how they are conceptualized, life stages are always used to define what is considered a normal developmental progression through life, sharing a good deal of overlap with the cultural concept of biography and cultural life script perspectives; that is, what constitutes a good life. McLean and Syed (2015) labeled this type as biographical master narrative, because it structures and governs how a life ought to proceed in the long term. Importantly, these biographical master narratives by and large define a "good life" according to the experiences of those who hold power and privilege (see also Cooper, Brown, Azmitia, \& Chavira, 2005). In Arnett's historical and cultural analysis, it is clear that the life course of men was used as the basis for defining the normative life progression; to the extent that women were (are) included it is largely in terms of their roles in relation to men (Syed, 2016). In other words, what is prescribed for the many actually only describes the few. The same can be seen with the biographical master narrative of the American Dream in the U.S. This narrative communicates that a valued life is one that represents success through hard work and a life progression that follows a specific sequence (school, work, marriage, house, kids). But this is clearly a narrative that only fits the experience of a small number of Americans privileged by 
race, class, gender, and sexuality. This is one of the ways in which Ronald's narrative represents a deviation from the master narrative, as his early failures in school violates this expected progression. But that is not the end of the story; due to subsequent events, the violation is repaired through a narrative of delayed maturation and framing as a narrative of redemption. Thus, one master narrative is used to account for the deviation from another (see also McLean et al., in press), with the end result being a societally sanctioned personal narrative (i.e., one of redemption).

Thus, master narratives fundamentally provide guidance about how to live a good lifethe precise territory of ethics. So what is the relation between master narratives and ethics? Master narratives can be thought of as ethical frames that function as ready-made templates through which ethical notions of the good life can be internalized as one's own, blurring the lines between public and private domains (more on that below). This latter point exposes a critical distinction: ethical principles can exist in the abstract sense, but master narratives help us understand how abstract ethical principles are applied to individuals' experiences, and can become individuals' ethical principles. Importantly, fitting with the themes of culture, power, and agency inherent to master narratives, the process by which society's ethical principles become individuals' ethical principles is largely outside of the individuals' control without massive and intentional effort (e.g., consciousness raising on a large scale; Seider, El-Amin, \& Kelly, this volume). Cultural institutions provide the broad outlines for acceptable ethical beliefs and behaviors, and these outlines include ethical constraints.

Work on ethics-based moral decision-making illustrates this point. Jensen’s (2011) cultural-developmental template approach to moral development indicates three broad sources for moral reasoning, labeled the ethics of autonomy, community, and divinity. These three ethics 
are seen as universal in their presence—-they are evident throughout all cultures—but are culturespecific in their prevalence of use (e.g., a cultural community may rely heavily on autonomy and community, but very little on divinity). Applying this model to Ronald's education narrative at the opening of the chapter clearly reveals that he was largely using the ethics of autonomy to guide his decision-making, with little or no reliance on the ethics of community or divinity. This ethical template is not problematic prima facie, but from a master narrative perspective it is notable what is left out: the violations to the ethic of community. There is little acknowledgement of the harm done to the family, and certainly no evidence of seeking to repair that harm. Additionally, there is no inclusion of the ethic of divinity, suggesting that he does not rely on the divine to reason about his life. Rather, this is a master narrative about autonomy - so much so that it is not only that autonomy can get you into trouble, but also autonomy can also get you out of trouble. Moreover, that autonomy grounds a narrative of self-exploration, choice, and self-realization that corresponds to American notions of the good life (e.g., Ryan \& Deci, 2000).

Yet Ronald's narrative is not only about autonomy, but about autonomy at the expense of community. The autonomous growth exhibited through the narrative could only come about by rejecting the desires and expectations of his parents and the broader society about how one should "do" college. Thus, ethics are imbued throughout the master narrative represented in Ronald's personal narrative, both in what is foregrounded (autonomy), and what is not (community, divinity). From this perspective, one can read narratives for both what is silenced and what is voiced, learning something about the larger culture from both lenses (Fivush, 2000).

The purpose of this section was to make the case for our proposition that there is a close connection between ethics and master narratives. Indeed, because master narratives act as the communicative tool for ethical principles, or the mechanism through which ethics go from 
society to individual, the two are very difficult to separate. So master narratives are fundamentally about ethics. That said, in what ways do they implicate morality?

\section{Proposition 2: While all master narratives are ethics-related, not all master narratives concern moral principles.}

We argued above that master narratives are fundamentally about ethics; the meaning and purpose of a good life. Because morality is a subset of ethics, master narratives can be about morality but master narratives are also often not about morality. To put it another way, while all master narratives are ethics-related, not all master narratives concern the twin moral principles of justice/fairness and harm avoidance/benevolence. Master narratives can pertain to other, more varied aspects of a good life, including aspects of the good life that aren't necessarily moral at all, such as personal autonomy.

Two distinctions between moral and other aspects of ethics are worth considering here. First, there are what have been viewed as fundamental or first-order moral concerns, those that are evident in all cultures and are acknowledged by most people as early as preschool age. These consist of the obligation to be fair or just and the obligation to avoid harming others. Even very young children argue that 1) it is not morally acceptable to harm others or to be unfair; 2) that harm and unfairness are not morally acceptable anywhere or any time; and 3) that harm and unfairness are not morally acceptable even if there are no laws addressing them, or if there are laws allowing harm and unfairness (see, e.g., Smetana, 2006; Turiel, 1998). These fundamental moral concerns can be contrasted with other issues, such as the conventional and pragmatic (social norms and rules that allow smooth functioning within a society, such as traffic rules), the prudential (the need to avoid harm to the self, relevant to health behaviors like avoiding smoking and drug abuse), and the personal (issues that can be determined by personal choice and 
preference, such as clothing choices) ${ }^{2}$. So, the moral concerns with unfairness and harm reflect a distinct and limited subset of broader concerns with what might constitute a good life (Bauer \& McAdams, 2005; Appiah, 2006; Wolf, 1982), while ideas about a good life might well invoke conventional, prudential, and personal concerns. Likewise, master narratives may involve many of these competing concerns. For example, Ronald's narrative of autonomy, which we established in the previous section as pertaining to ethics and both violating and aligning with master narratives, is not directly about morality with respect to how he narrates it ${ }^{3}$. Thus, although autonomy may be used as an ethical source from which to conceptualize the moral agent and engage in moral reasoning, autonomy, per se, is not a moral concern (see Nucci, 1982).

Despite these well-established distinctions, and evidence that people can make these distinctions easily under controlled circumstances, a master narrative approach raises important questions about the ways in which people do not always neatly distinguish between what is truly moral and truly obligatory, and what is convention, prudence, or personal preference, or what is morally good but not required. As we consider next, even when a master narrative arguably doesn't directly concern issues of unfairness or harm, the master narrative can take on moral force. By this, we mean that the master narrative, and conformity/congruence with that master narrative, has the potential to become not only an ethical imperative, but also a moral one. Next, we consider why and how the moralization of master narratives is likely.

\footnotetext{
2 The labels for some of these domains have been altered in recent years; the conventional domain is referred to as "societal" and the personal domain "psychological" (Smetana, 2006). Our view is that these new labels make the distinction less clear rather than more clear, given that all domains intersect with both psychological and societal processes.

${ }^{3}$ The harm to parents embedded into the story could be viewed in moral terms, but the redemptive nature of the story implies that this harm was not long-lasting, despite the fact that the issue was never explicitly discussed.
} 


\section{Proposition 3: Although not always intrinsically moral, master narratives can come to exert moral force}

What does it mean that a master narrative can come to exert moral force? In the simplest terms, it means that master narratives that do not directly implicate moral concerns can have moral implications when they are violated. Thus, the morality comes into play less in the content of the master narrative, but in the process of deviating from it. Moreover, there can be a moral obligation to conform to the master narratives that has implications for development.

This assertion rest on the assumption that, in addition to potential explicit morality, there is an implicit morality wrapped up in the phenomena of aligning with and deviating from master narratives. How might such moral messages arise for master narratives that are not, on the surface, concerned with injustice/unfairness or harm? We suggest that this implicit morality, in particular, arises for several reasons that have to do with the nature of narratives in general, and of master narratives in particular.

The ubiquity of master narratives implies that their architecture is equally available to all. The compulsory nature of master narratives suggests that people must account for deviations from the master narratives. These two features mean that master narratives intrinsically convey a sense of choice and agency. Because narratives in general concern the doings of agents, as they pursue their goals and aims and encounter obstacles and frustrations, the potential for narratives to convey a sense that narrators are responsible for their own experiences is large.

Narratives in general involve complex situations that evoke many types of concerns personal, conventional, prudential, and moral. Further, narratives take an evaluative stance on the matters they concern (Bruner, 1990; Tappan, Freeman, 1993). That is, narratives convey who, what, when, where, why, and how in ways that are intimately tied to whether the entire affair 
was good, bad, or somewhat muddled. Master narratives are no exception—-the conventional life narrative embodied in the cultural script research not only conveys what 'a typical life' is like, but also what 'a good life' is like. Further, we noted earlier that people can distinguish between different kinds of good - good in the moral sense, versus good in the conventional, prudential, or personal sense. However, there is also ample reason to believe that people do not always successfully, readily, or adequately draw such distinctions in the complex situations that constitute their everyday lives. Consider the opening example, in which many potential concerns - moral, personal, and conventional - might be implied, but the overall experience is evaluated as "the best thing that ever happened to me" in ways that leave ambiguous which concerns have been well served by the event. In fact, there are several ways in which people can imbue issues that are not necessarily moral with moral emotions (e.g., guilt and shame) and evaluations, and considering those ways illuminates how master narratives might acquire moral force. Virtually all of these ways that the moral and the non-moral become intertwined entail at least one of two components - rendering some action narratively as a matter of choice and agency on the part of the actor, and/or highlighting the way in which that action or inaction promotes harm or injustice. Master narratives can create both of those components. Below we illustrate this by considering how personal, conventional, and prudential issues can come to take on moral force through their enmeshment with master narratives.

Personal: What I find right is what is right for all. People can sometimes confuse what is "good for me" with what is "right and required for people in general". Given the wealth of findings on false consensus bias (Marks \& Miller, 1987), the notion that what I find good is what others should find good may play a role in how master narratives function. Because master narratives typically reflect the good story and the good life for those in power - the majority, the 
privileged - master narratives can come to tacitly impose the good for some, on a larger and more diverse set of people for whom those goods may be problematic (Syed, 2016).

To return to Ronald's story, it may be good for many to go directly through college without excessive partying, but for others, the "excessive” partying year may provide some needed space for growth and maturation, or even exploration. For still others, a life path that traverses through a young adult college education may be a poor fit. Yet the master narrative that college is an important set of experiences in the path of a good life is implicitly informing public policy about education within the U.S. (and perhaps suppressing a move towards more comprehensive and useful vocational educational opportunities).

One implication of thinking about ethics and morality from a master narrative perspective is that it more clearly threads the personal domain into the conventional and prudential in the context of moral issues. We illustrate how this works as we take the conventional and prudential domains in greater detail.

\section{Conventional: What we all do seems like the right thing to do. It has been} documented that people can connect what most people do with ideas about what is morally good (see Shweder, Mahapatra, \& MIller, 1990). Although what it means that people connect what we all do, with what is right to do has been variously debated by moral researchers (e.g., Shweder, 1990; Turiel et al., 1987), our point here is not to address that debate, but to merely note that for most people, what is typical and usual takes on moral overtones (see also Bear \& Knobe, 2016). Thus, because one of the central features of master narratives is ubiquity, master narratives again take on moralization potential by the virtue of their basic, foundational features.

For example, childlessness is a violation of the conventional practice of having children, where for many having children is a simple fact of existence versus an issue deeply deliberated 
(Park, 2002). Accordingly, violations of this convention, particularly when voluntary, can be viewed by others with moral outrage (Ashburn-Nardo, 2016). Notably, childlessness is not only a violation of the narrow convention of having children, but also of the broader biographical master narrative of the life course (Arnett, 2016; McLean \& Syed, 2015). If someone does not have children, how can they move through other aspects of a good life story - watching children grow up, or becoming grandparents? What will they do with themselves when everyone else is watching the middle school play? How will they contribute to the continuity of society? The violation of the broader biographical master narrative raises such questions for the childless person as well as for those around him or her - and such questions span both ethical considerations about the quality of a life, and moral questions about obligations to society. Further, the ubiquity of children in the biographical master narrative - even across distinct cultures (see, e.g., Ottsen \& Berntsen, 2014), implies that having children is widely available to everyone, and beneficial for individuals and societies, despite some evidence that such benefits for individuals are complicated by personal costs (Nelson, Kushlev, \& Lyubomirsky, 2014), as well as the clear fact that having a child is not an option for everyone.

Importantly, from a master narrative perspective what is common is not simply defined by its statistical regularity. "What we all do" is defined within a society that affords unequal access to power amongst its members. For example, in the U.S. there is a long history of the presence and involvement of African Americans, Native Americans, non-European immigrants, and atheists/agnostics, and yet none of these groups are seen as typical or normative within the American context (e.g., Devos \& Banaji, 2005), and in many cases, these groups do not experience their lives in ways that align with the biographical master narrative. Again, as we noted above, what is prescribed for the many actually only describes the few. Thus, to 
understand how conventional concerns take on moral force, we must go beyond pure frequencies of events, and consider the history and context of societal power and how that interacts with agency.

Prudential: Issues of risk and personal harm are also moral. When master narratives concern prudential issues, which involve concerns about risk and self-harm, they are also easily moralized. One clear reason for this is that harming others is seen as wrong and has moral implications, and it is fairly easy to extend notions of harm to others to prudential issues and harm to the self. In addition, taken to a collective level, prudential issues can be cast as harmful to the collective via their harm to individuals. For example, obesity is framed as the end result of a matter of individual choices and responsibilities that affect the individual's well-being (Mulder, Rupp, Djikstra, 2015). The slogan “eat less and move more” conveys a skeletal master narrative about how someone becomes overweight. That master narrative can become moralized, however, in emphases on the public costs of obesity-related disease. When one is likely to incur those costs for the collective for reasons that are attributed to personal choices, as opposed to structural inequalities (e.g., access to affordable and healthy food, or to preventative health care), the result is moralization of obesity. Again, the twin aspects of personal choices and impact (harm or unfairness) on others come to the forefront.

When applying a master narrative framework to such dynamics, these twin features again becomes visible and relevant. While the master narrative about obesity as a matter of immoral choices leading to societal harm is a relatively new story, similar master narratives emerged around smoking (Rozin, 1999), in ways that moralized what might previously be seen as a matter of personal preference. Further, these moralized narratives also obscure the role of institutions in promoting individual's risk and constraining or shaping individual choices; in the cases of 
obesity and cigarette smoking, institutional and corporate actions also played (and play) a large role.

And of course such examples are not restricted to the health context. In the U.S. context individuals from poor and working class backgrounds are seen to be a product of their own, maladaptive choices and individual dispositions of being lazy and lacking motivation to change (Bullock, 2008). In this sense, they are seen as having engaged in a form of self-harm that also threatens the collective well-being by being a "drain on the system” and disproportionately requiring investment of societal resources. Such a link is a violation of the "success through hard work and determination” aspect of the American Dream. A master narrative framework helps draw attention to the overvaluing of choice and agency, and how individuals draw a link between these prudential issues and collective welfare to make moral judgements.

\section{A Master Narrative Approach Must Also Consider Alternative Narratives}

Throughout this chapter we have explicitly emphasized the dynamic between master narratives and personal narratives. However, master and personal narratives represent only two of the three core components of the master narrative framework. We emphasized these two components given the primary goal of the chapter was to communicate how moral development interfaces with master narratives specifically, but the third component, alternative narratives, must also be considered when adopting the master narrative framework (McLean \& Syed, 2015). Alternative narratives are culturally-available story templates that do not reflect the dominant, mainstream perspective. In many cases, they are counter narratives, in that they are explicitly motivated to resist the oppressive features of the master narratives (Bamberg \& Andrews, 2004). But how do such alternative narratives come to generate sufficient force to have an influence on 
the master narratives? We highlight two routes here, using master narratives that may not appear to be in the moral domain on their faces, but have come to take on moral force.

The first route for alternative narrative generation is when the master narrative begins to be overwhelmed by sheer numbers. Once again we can draw upon the master narrative of the American Dream, which as we just argued, takes on moral force within the prudential domain. A critical feature of this master narrative is the idea that individuals can succeed and live a good life as long as they are determined and work sufficiently hard. While this master narrative has always been problematic, in recent years there has been increased awareness and discussions of the substantial limitations to the underlying message. "Success through hard work" has been resisted with the motto of "income inequality" and a corresponding narrative that rejects the individualized view of the master narrative of the American Dream in favor of a systemic view of success that focuses on corporate legitimacy and a rigged system (e.g., Shrivastava \& Ivanova, 2015). What is interesting about this example vis-à-vis moral development is that the alternative narrative flips the moral responsibility: within the master narrative of the American Dream the moral violation rests with the lazy unmotivated people who threaten our collective welfare, but in the alternative narrative the moral violation rests with those who hold social, economic, and political power ("the 1\%") and use their power for dominance rather than welfare. At the current historical moment these two narratives are deeply embattled, but as more and more people realize that their life is not working out the way the canonical master narrative works, the alternative narratives is likely to gain greater strength.

The second route for alternative narrative generation is active, organized resistance. A clear example is the historical narratives surrounding LGBT identities. A master narrative of choice in sexual identities enabled an attribution of deviancy to those individuals and facilitated 
repressive and restrictive social policies and practices (e.g., denial of partner benefits, conversion therapy). The choice is also cast as having moral implications, particularly with respect to the potential harmful influence on children. It was against this master narrative of choice that the alternative narrative of born this way was developed and popularized (Lemke, 2016; cf; Gaga \& Laursen, 2011). This alternative narrative gained substantial traction and was (is) effective in shifting attitudes and policies that implicate LGBT individuals (Bennett, 2014; Schilt, 2015). In addition to again shifting the moral responsibility from the target to the perpetrator, what is interesting about this example is that the born this way alternative narrative was nearly immediately rejected among many LGBT individuals, if seriously ever endorsed at all (Bennett, 2014). That is, despite its political utility, it is an essentialized narrative identity that runs counter to the long history of identity, gender, and sexuality being characterized as fluid and socially constructed within the LGBT community (Bennett, 2014). Thus, there are multiple alternative narratives that can be endorsed and used in different ways, all in service of resisting the master narrative.

We use these two examples to highlight three points about the dynamic between master narratives and alternative narratives. First, even though master narratives are rigid, and thus have staying power, the rigidity of master narratives can be challenged and threatened by alternative narratives, if they gain enough force. The associated change may be slow, incremental, and painful, but change can happen as individuals put pressure on the master narrative by increasingly rejecting it in favor of the alternative. One approach to facilitating this change is to focus on developing individuals' critical consciousness, which includes critical reflection on how society functions, political self-efficacy, and sociopolitical action (Seider et al., this volume). Second, because the content of master narratives isn't always obviously moral, the moral force 
they exert can be tacitly enforced and applied, making resistance and negotiation from individuals against the master narrative more challenging. This point is related to the third: as illustrated in our examples, master narratives that take on moral force perhaps must be resisted, in part, by transferring the moral responsibility. This means that popularization of the alternative narrative involves surfacing the tacit moral force of the master narrative and making the implicit explicit so that moral blame can be reassigned (or eliminated altogether). This last point, in particular, is preliminary and provocative, but worthy of consideration as the master narrative framework continues to develop.

\section{Future Directions}

In this chapter we advanced numerous ideas anchored in the three propositions that serve as the core of our argument. Many of these ideas were based on synthesizing existing theory and research, rather than on direct empirical data, per se. Thus, an important avenue for future research is to ask questions and conduct tests that directly flow from the three propositions.

A first step in doing so, however, is to engage in descriptive work that maps different master narratives that are active in the culture of interest. Indeed, this is needed in all research on master narratives, not just work that pertains to morality (McLean \& Syed, 2015). With respect to morality, master narratives would need to be conceptualized and understood in terms of their ethical and moral content. From there, we can examine the processes by which ethical principles that are embedded within master narratives become internalized into individual personal narratives and then are subsequently used to make moral judgements about the self and other. A general approach such as this would be the most direct test of our propositions.

However, there are other fruitful ways forward. For example, a useful approach could involve narrowing in on individuals who are actively constructing alternative narratives. Master 
narratives and alternative narratives are dialectical, and thus master narratives can come into greater relief when examined in terms of how, when, and why people deviate from them (McLean \& Syed, 2015; McLean et al., in press). From this perspective, examining the moral reasoning involved in rejecting a master narrative and adopting an alternative narrative would provide some insights into the ethical and moral content of the master narratives. Research on the development of critical consciousness would be a prime area for this kind of work, which thus far has focused more on current attitudes and behaviors rather than reasoning about how and why they came to think that way in the first place (Seider et al., this volume).

This latter example raises the importance of thinking developmentally about master narratives and how they interface with ethics and morality. In the example of critical consciousness, the developmental process involves awareness and recognition of structural forces and societal inequities (as embodied by master narratives), followed by a motivated desire to do something about it. This sequence may indeed underlie the general process of moving one's personal narrative to be more aligned with an alternative, rather than master narrative. Moreover, the moral significance individuals attach to the master narratives may be associated with their willingness to deviate, as doing so may potentially be seen not only as a threat to the self, but threat to relations with family, friends, and communities. Regardless of how researchers approach it, understanding developmental factors associated with master narratives, ethics, and morality may optimally be understood during those times of deviation and disruption (see also Kunnen \& Metz, 2015).

Finally, as research on master narratives, ethics, and morality progresses, it will be valuable to examine the issue from multiple levels of analysis. That is, master narratives can be understood through analysis of broad cultural products and representations (McAdams, 2006), 
individuals' stories told about their past experiences (McLean et al., in press), individual reflections on current events (McLean, Shucard, \& Syed, 2017), and in vivo conversations between people (Bamberg, 1997; DiBianca Fasoli, this volume). Moreover, master narratives could be investigated using a method that is popular in the moral development literature, particularly in domain theory: vignettes through which individuals make moral judgments. These vignettes could be modified to depict conformity and deviation from master narratives to investigate how individuals reason about such situations. Given that master narratives are threaded through all aspects of livelihoods, from the societal to the interactional, such an expansive approach to understanding them is necessary.

\section{Conclusion}

The purpose of this chapter was to explore how master narratives can have both ethical and moral implications, and can provide a way for researchers to look at the intersections among culture, ethics and morality, and individual development. Given that this is a new synthesis, many of the ideas presented are speculative and meant to be generative. That is, we hope the ideas and connections presented will generate new and different ways of thinking about the way we study and understand moral and ethical development. 


\section{References}

Appiah, K. A. (2006). Cosmopolitanism: Ethics in a world of strangers. New York, NYC: W.W. Norton and Company.

Arnett, J. J. (2016). Life stage concepts across history and cultures: Proposal for a new field on indigenous life stages. Human Development, 59(5), 290-316.

Ashburn-Nardo, L. (2016). Parenthood as a moral imperative? Moral outrage and the stigmatization of voluntarily childfree women and men. Sex Roles, 1-9.

Bamberg, M. G. (1997). Positioning between structure and performance. Journal of Narrative and Life History, 7(1-4), 335-342.

Bamberg, M., \& Andrews, M. (Eds.). (2004). Considering counter-narratives: Narrating, resisting, making sense (Vol. 4). John Benjamins Publishing.

Bauer, J. J., McAdams, D. P., \& Sakaeda, A. R. (2005). Interpreting the good life: growth memories in the lives of mature, happy people. Journal of Personality and Social Psychology, 88(1), 203.

Baumeister, R. F., Stilman, A., \& Wotman, S. R. (1990). Victim and perpetrator accounts of interpersonal conflict: Autobiographical narratives about anger. Journal of Personality and Social Psychology, 59, 994-1005.

Bear, A., \& Knobe, J. (2016). Normality: Part descriptive, part prescriptive. Cognition. Online First

Bennett, J. (2014). “Born This Way”: Queer vernacular and the politics of origins. Communication and Critical/Cultural Studies, 11(3), 211-230.

Bronfenbrenner, U. (1979). The ecology of human development: Experiments by nature and design. Cambridge, MA: Harvard University Press.

Bruner, J. S. (1990). Acts of meaning (Vol. 3). Harvard University Press.

Bullock, H. E. (2008). Justifying inequality: A social psychological analysis of beliefs about poverty and the poor. In A. C. Lin \& D. R. Harris (Eds.),The colors of poverty: Why racial and ethnic disparities persist (pp. 52-76). New York: Russell Sage Foundation.

Colby, A., \& Damon, W. (1992). Some do care: Contemporary lives of moral commitment. New York: Free Press.

Cooper, C. R., Brown, J., Azmitia, M., \& Chavira, G. (2005). Including Latino immigrant families, schools, and community programs as research partners on the good path of life (el buen camino de la vida). In T. Weisner (Ed.), Discovering successful pathways in 
children's development: Mixed methods in the study of childhood and family life (pp. 359-422). Chicago: University of Chicago Press.

Devos, T., \& Banaji, M. R. (2005). American= white? Journal of Personality and Social Psychology, 88(3), 447.

Dworkin, R. (1986). Law’s Empire. Cambridge, MA: Harvard University Press

Eisenberg, N., Carlo, G., Murphy, B., \& Van Court, P. (1995). Prosocial development in late adolescence: A longitudinal study. Child Development, 66, 1179-1197.

Fivush, R. (2000). Accuracy, Authority, and Voice: Feminist Perspectives on Autobiographical memory. In P. H. Miller \& E. Kofsky Scholnick (Eds.), Toward a Feminist Developmental Psychology (pp. 85-105). Florence, KY, US: Taylor and Francis/Routledge.

Freeman, M. (1993). Rewriting the self: History, memory, narrative. London: Routledge.

Gaga, L., \& Laursen, J. (2011). Born this way [Recorded by Lady Gaga]. On Born this way. London: Abbey Road Studios.

Govier, T. (2002). Forgiveness and Revenge. London, England: Routledge.

Habermas, T., \& Köber, C. (2015). Autobiographical reasoning is constitutive for narrative identity: The role of the life story for personal continuity. In K. C. McLean \& M. Syed (Eds.)., The Oxford handbook of identity development. New York: Oxford University Press.

Habermas, T., \& Reese, E. (2015). Getting a life takes time: The development of the life story in adolescence, its precursors and consequences. Human Development, 58(3), 172-201.

Hammack, P. L. (2008). Narrative and the cultural psychology of identity. Personality and Social Psychology Review, 12(3), 222-247.

Hammack, P. L. (2011). Narrative and the politics of identity. New York City, NY: Oxford University Press.

Hardy, S. A., \& Carlo, G. (2005). Identity as a source of moral motivation. Human Development, 48, 232-256.

Hatiboğlu, N., \& Habermas, T. (2016). The normativity of life scripts and its relation with life story events across cultures and subcultures. Memory, 24(10), 1369-1381.

Jensen, L. J. (2011). The cultural-developmental theory of moral psychology: A new synthesis. In. L. A. Jensen (Ed.), Bridging cultural and developmental approaches to psychology (pp. 3-25). New York. Oxford University Press. 
Jensen, L. A., \& McKenzie, J. (2016). the moral reasoning of US Evangelical and mainline Protestant children, adolescents, and adults: A cultural-developmental study. Child Development, 87(2), 446-464.

Kunnen, E. S., \& Metz, M. (2015). Commitment and exploration: The need for a developmental approach. In K. C. McLean \& M. Syed (Eds.), The Oxford handbook of identity development (pp. 115-131). New York: Oxford University Press.

Laible, D. J., \& Thompson, R. A. (2002). Mother-child conflict in the toddler years: Lessons in emotion, morality, and relationships. Child Development, 73, 1187-1203.

Lemke, C. (2016). Not born this way: Exploring an alternative discourse of surprise in onceheterosexual-identified women's narratives. The Journal of American Culture, 39(1), 2032.

Marks, G., \& Miller, N. (1987). Ten years of research on the false-consensus effect: An empirical and theoretical review. Psychological Bulletin, 102(1), 72-90.

Markus, H. R., \& Kitayama, S. (1991). Culture and the self: Implications for cognition, emotion, and motivation. Psychological Review, 98(2), 224-253.

McAdams, D. P. (2006). The redemptive self: Stories Americans live by-revised and expanded edition. Oxford University Press.

McAdams, D. P. (2013). The psychological self as actor, agent, and author. Perspectives on Psychological Science, 8(3), 272-295.

McLean, K. C., Lilgendahl, J. P., Fordham, C., Alpert, L., Marsden, E., \& Szymanowski, K., \& McAdams, D. P. (in press). Identity development in cultural context: The role of deviating from master narratives. Journal of Personality.

McLean, K. C., \& Pasupathi, M. (2012). Processes of identity development: Where I am and how I got there. Identity, 12(1), 8-28.

McLean, K. C., Pasupathi, M., \& Pals, J. L. (2007). Selves creating stories creating selves: A process model of self-development. Personality and Social Psychology Review, 11(3), 262-278.

McLean, K.C., Shucard, H., \& Syed, M. (2017). Applying the master narrative framework to gender identity development in emerging adulthood. Emerging Adulthood, 5(2) 93-105. 
McLean, K. C., \& Syed, M. (2015). Personal, master, and alternative narratives: An integrative framework for understanding identity development in context. Human Development, 58, 318-349.

Mulder, L. B., Rupp, D. E., \& Dijkstra, A. (2015). Making snacking less sinful: (Counter-) moralising obesity in the public discourse differentially affects food choices of individuals with high and low perceived body mass. Psychology \& Health, 30(2), 233251.

Narvaez, D., \& Lapsley, D. (2014). Becoming a moral person-Moral development and moral character education as a result of social interactions. In Christen, M., Van Schaik, C., Fischer, J., Huppenbauer, M., \& Tanner, C. (Eds.). Empirically informed ethics: Morality between facts and norms (pp. 227-238). Springer International Publishing.

Nelson, S. K., Kushlev, K., \& Lyubomirsky, S. (2014). The pains and pleasures of parenting: When, why, and how is parenthood associated with more or less well-being? Psychological Bulletin, 140(3), 846-895.

Nisbett, R. E., \& Cohen, D. (1996). Culture of honor: The psychology of violence in the South. Boulder, CO US: Westview Press.

Nucci, L. (1981). Conceptions of personal issues: A domain distinct from moral or societal concepts. Child Development, 52, 114-121.

Ottsen, C. L., \& Berntsen, D. (2014). The cultural life script of Qatar and across cultures: Effects of gender and religion. Memory, 22(4), 390-407.

Park, K. (2002). Stigma management among the voluntarily childless. Sociological Perspectives, 45(1), 21-45.

Pasupathi, M., \& Wainryb, C. (2010). Developing moral agency through narrative. Human Development, 53, 55-80.

Pasupathi, M., Wainryb, C., Bourne, S., \& Posada, R. (in press). Narrative construction of morality in adolescence among typically-developing and violence-exposed youth. Imagination, Cognition, and Personality.

Reese, E., Bird, A., \& Tripp, G. (2007). Children's self-esteem and moral self: Links to parentchild conversations. Social Development, 16(3), 460-478.

Recchia, H. E., Wainryb, C., Bourne, S., \& Pasupathi, M. (2014). The construction of moral agency in mother-child conversations about helping and hurting across childhood and adolescence. Developmental Psychology, 50, 34-44. 
Recchia, H. E., Wainryb, C., \& Pasupathi, M. (2013). "Two for flinching": Children's and adolescents' narrative accounts of harming their friends and siblings. Child Development, 84, 1459-1474.

Rozin, P. (1999). The process of moralization. Psychological Science, 10(3), 218-221.

Ryan, R. M., \& Deci, E. L. (2000). Self-determination theory and the facilitation of intrinsic motivation, social development, and well-being. American Psychologist, 55(1), 68-78.

Schachter, E. P. (2015). Integrating “internal,”“interactional,” and “external” perspectives: Identity process as the formulation of accountable claims regarding selves. In K. C. McLean \& M. Syed (Eds.), The Oxford handbook of identity development. New York: Oxford University Press.

Schilt, K. (2015). Born This Way: Thinking Sociologically about Essentialism. Emerging Trends in the Social and Behavioral Sciences: An Interdisciplinary, Searchable, and Linkable Resource.

Shrivastava, P., \& Ivanova, O. (2015). Inequality, corporate legitimacy and the Occupy Wall Street movement. Human Relations, 68(7), 1209-1231.

Shweder, R. A. (1990). Ethical relativism: Is there a defensible version?. Ethos, 18(2), 205-218.

Shweder, R. A. (2000). The psychology of practice and the practice of the three psychologies. Asian Journal of Social Psychology, 3(3), 207-222.

Shweder, R. A. , Mahapatra, M., \& Miller, J. G. (1990). Culture and moral development. In J. W. Stigler, R. A. Shweder, \& G. Herdt (Eds.), Cultural psychology: Essays on comparative human development (pp. 130-204). Cambridge, UK: Cambridge University Press.

Smetana, J. (2006). Social-cognitive domain theory: Consistencies and variations in children's moral and social judgments. In M. Killen \& J. Smetana (Eds.), Handbook of moral development (pp. 119-154). Mahwah, NJ: LEA.

Syed, M. (2016). Power and agency in conceptualizing life stages as master narratives. Human Development, 59, 317-323.

Tappan, M. B., \& Packer, M. J. E. (1991). Narrative and storytelling: Implications for understanding moral development. San Francisco: Jossey-Bass.

Thorne, A., \& McLean, K. C. (2003). Telling traumatic events in adolescence: A study of master narrative positioning. In R. Fivush \& C Haden (Eds.), Autobiographical memory and the construction of a narrative self: Developmental and cultural perspectives, (pp. 169-185). Mahwah, NJ: Erlbaum. 
Thorne, A., \& Nam, V. (2006). The storied construction of personality. In P. Corr, \& G. Matthews (Eds.), Cambridge handbook of personality. Cambridge: Cambridge University Press.

Turiel, E. (1998). The development of morality. In W. Damon \& N. Eisenberg (Eds.), Handbook of child psychology, 5th Ed., Social, emotional, and personality development (pp. 863932). New York: John Wiley \& Sons, Inc.

Wainryb, C., Brehl, B., \& Matwin, S. (2005). Being hurt and hurting others: Children's narrative accounts and moral judgments of their own interpersonal conflicts. Monographs of the Society for Research in Child Development, 70.

Wolf, S. (1982). Moral Saints. The Journal of Philosophy, 79, 419-439 